\title{
Erythropoietin Treatment Exacerbates Moderate Injury after Hypoxia-Ischemia in Neonatal Superoxide Dismutase Transgenic Mice
}

\author{
R. Ann Sheldon ${ }^{a, c}$ Christine Windsor ${ }^{a, c}$ Byong Sop Lee ${ }^{a, c, d}$ \\ Olatz Arteaga Cabeza ${ }^{\mathrm{e}}$ Donna M. Ferriero ${ }^{\mathrm{a}-\mathrm{c}}$
}

Departments of a Pediatrics and ${ }^{\mathrm{b}}$ Neurology and ${ }^{\mathrm{C}}$ Newborn Brain Research Institute, University of California San Francisco, San Francisco, CA, USA; d Department of Pediatrics, University of Ulsan College of Medicine, Asan Medical Center, Seoul, South Korea; ${ }^{\mathrm{e}}$ Department of Cell Biology and Histology, School of Medicine and Dentistry, University of the Basque Country, Leioa, Spain

\section{Keywords}

Brain injury $\cdot$ Erythropoietin $\cdot$ Hypoxia-ischemia $\cdot$ Mouse . Superoxide-dismutase

\begin{abstract}
The neonatal brain is highly susceptible to oxidative stress as developing endogenous antioxidant mechanisms are overwhelmed. In the neonate, superoxide dismutase (SOD) overexpression worsens hypoxic-ischemic injury due to $\mathrm{H}_{2} \mathrm{O}_{2}$ accumulation in the brain. Erythropoietin (EPO) is upregulated in 2 phases after $\mathrm{HI}$, early ( $4 \mathrm{~h}$ ) and late (7 days), and exogenous EPO has been effective in reducing the injury, possibly through reducing oxidative stress. We hypothesized that exogenous EPO would limit injury from excess $\mathrm{H}_{2} \mathrm{O}_{2}$ seen in SOD1-overexpressing mice, and thus enhance recovery after $\mathrm{HI}$. We first wanted to confirm our previous findings in postnatal day 7 (P7) SOD-tg (CD1) mice using a P9 model of the Vannucci procedure of HI with SODtg mice from a different background strain (C57BI/6), and then determine the efficacy of EPO treatment in this strain and their wild-type (WT) littermates. Thus, mice overexpressing copper/zinc SOD1 were subjected to $\mathrm{HI}$, modified
\end{abstract}

\section{KARGER}

(C) 2017 S. Karger AG, Basel

E-Mail karger@karger.com

www.karger.com/dne for the P9 mouse, and recombinant EPO $(5 \mathrm{U} / \mathrm{g})$ or vehicle (saline) was administered intraperitoneally 3 times: at $0 \mathrm{~h}$, $24 \mathrm{~h}$, and 5 days. Injury was assessed 7 days after $\mathrm{HI}$. In addition, protein expression for EPO and EPO receptor was assessed in the cortex and hippocampus $24 \mathrm{~h}$ after HI. With the moderate insult, the SOD-tg mice had greater injury than the WT overall, confirming our previous results, as did the hippocampus and striatum when analyzed separately, but not the cortex or thalamus. EPO treatment worsened injury in SOD-tg overall and in the WT and SOD-tg hippocampus and striatum. With the more severe insult, all groups had greater injury than with the moderate insult, but differences between SOD-tg and WT were no longer observed and EPO treatment had no effect. Increased protein expression of EPO was observed in the cortex of SOD-tg mice given recombinant human EPO compared to SOD-tg given vehicle. This study confirms our previous results showing greater injury with SOD overexpression in the neonatal brain after $\mathrm{HI}$ at P7 in a different strain. These results also suggest that EPO treatment cannot ameliorate the damage seen in situations where there is excess $\mathrm{H}_{2} \mathrm{O}_{2}$ accumulation, and it may exacerbate injury in settings of extreme oxidative stress.

(c) 2017 S. Karger AG, Basel
R. Ann Sheldon

Neonatal Brain Disorders Laboratory, Department of Pediatrics Box 0663 University of California San Francisco, 675 Nelson Rising Lane, Room 494 San Francisco, CA 94158 (USA)

E-Mail ann.sheldon@ucsf.edu 


\section{Introduction}

The enzyme $\mathrm{Cu} / \mathrm{Zn}$-superoxide dismutase (SOD1) catalyzes the removal of superoxide free radicals generated from mitochondrial respiration, and overexpression of SOD1 has been shown to be beneficial in models of adult ischemia [1]. However, we found overexpression of SOD1 to be detrimental in the setting of neonatal hypoxia-ischemia (HI) [2]. This lack of benefit from increased SOD1 is likely due to the accumulation of $\mathrm{H}_{2} \mathrm{O}_{2}$ seen in the neonatal brain [3] but not in the adult brain [4]. However, in addition to the detrimental effects of $\mathrm{H}_{2} \mathrm{O}_{2}$ on cell integrity and survival, the production of $\mathrm{H}_{2} \mathrm{O}_{2}$ modulates the stabilization and transcriptional activation of HIF- $1 \alpha$ [5], which regulates a number of protective genes that are responsible for homeostasis and also protection and repair after severe oxidative stress in neonatal ischemia. Low levels of $\mathrm{H}_{2} \mathrm{O}_{2}$, in particular, stabilize and/or upregulate HIF- $1 \alpha$, and thereby mediate HI preconditioning protection [6]. One of the genes regulated by HIF-1a is erythropoietin (EPO). EPO has been shown to reduce cellular injury in vitro [7-10] and to reduce brain injury in in vivo models of neonatal stroke [11-14] and HI [1519]. EPO may prevent cell death by inhibiting apoptosis. EPO binds to 2 cell surface receptors that form a homodimer that activates Jak2 kinase to phosphorylate both Jak2 and EPO receptor (EPOR). This activates multiple signaling cascades, including NF- $\kappa \mathrm{B}$ and Stat 5 , which move into the nucleus and act as transcription factors for the antiapoptotic genes $B c l-2$ and $B c l-x L$. EPO also reduces necrotic cell death induced by inflammation and it may promote neuroregeneration and angiogenesis [20].

While therapeutic hypothermia has become the standard of care for newborns with hypoxic-ischemic encephalopathy, it provides incomplete protection to many of the infants treated and may be ineffective in those with exacerbating factors such as intrauterine-acquired infection [21]. EPO shows promise as another therapy for neonatal hypoxic-ischemic injury [22]. A nonhuman primate study [23] and small clinical trials using a multidose regimen based on animal studies have established safety and pharmacokinetics when combined with therapeutic hypothermia [24], and this suggests that EPO may result in less MRI brain injury and improve 1-year motor function [25].

In more severe brain injury after neonatal $\mathrm{HI}$, there is increased oxidative stress. SOD1-overexpressing mice had increased oxidative stress due to the accumulation of $\mathrm{H}_{2} \mathrm{O}_{2}$ [3]. We hypothesized that injury after neonatal $\mathrm{HI}$ in situations of excess $\mathrm{H}_{2} \mathrm{O}_{2}$ accumulation could be ameliorated with exogenous EPO. To test this hypothesis, we

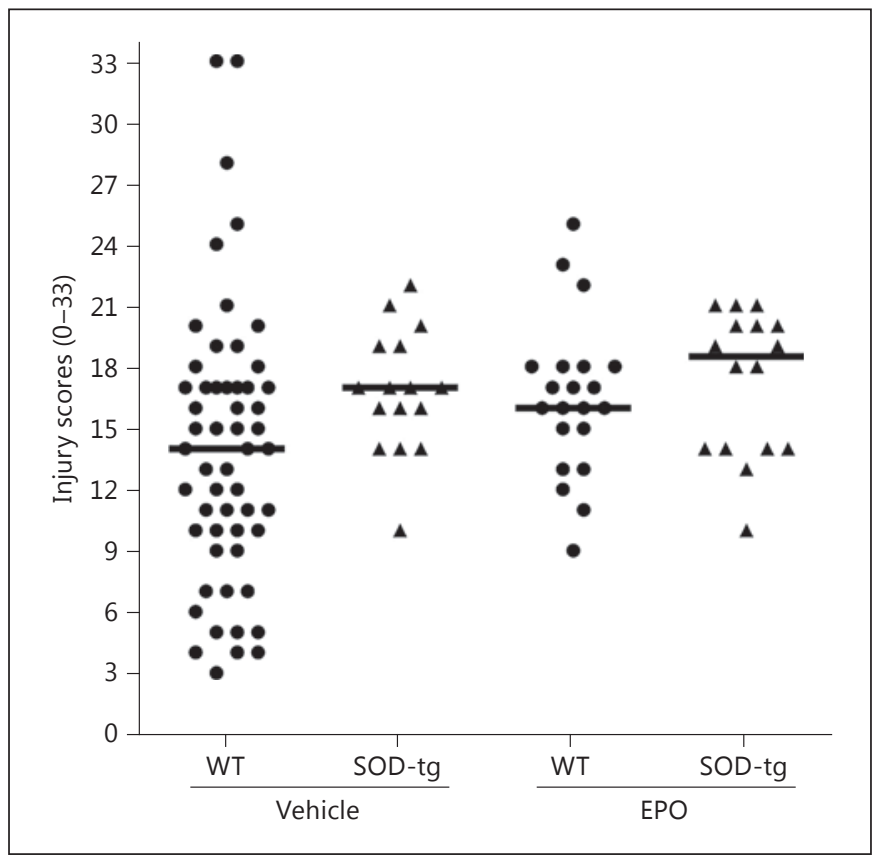

Fig. 1. Histological injury scores for the whole hemisphere after HI with 50-min hypoxia (scale 0-33). The horizontal line represents the median score. SOD-tg + vehicle was more injured than WT + vehicle $(p<0.03)$, as was WT + EPO $(p<0.05)$ and SOD-tg + EPO $(p=0.01)$.

chose to examine SOD1-overexpressing mice that accumulate excess $\mathrm{H}_{2} \mathrm{O}_{2}$, and we tested whether EPO could indeed reverse the severe damage seen in these brains.

\section{Materials and Methods}

Mice

Transgenic mice overexpressing human SOD1 (hSOD1-tg) and their wild-type (WT) littermates (C57/Bl6) were used for this study [26]. All procedures were approved by the Institutional Animal Care and Use Committee (IACUC) at UCSF, in accordance with NIH guidelines for the Care and Use of Laboratory Animals. Genotyping was performed by gel electrophoresis and protein staining for SOD1 as previously described [27].

\section{Hypoxia-Ischemia}

For histological analysis, mice underwent $\mathrm{HI}$ as previously described [28], with modifications for the postnatal day 9 (P9) mouse model [29]. Specifically, while under isoflurane anesthesia, the left carotid artery was exposed and permanently ligated by electrocoagulation. After a 1-h recovery period with the dam, the mice were placed in chambers floating in a water bath at $37^{\circ} \mathrm{C}$ and exposed to $10 \%$ oxygen and $90 \%$ nitrogen for either $50 \mathrm{~min}(n=109: 77 \mathrm{WT}$ and 32 SOD-tg) or $60 \mathrm{~min}$ ( $n=48: 22 \mathrm{WT}$ and 26 SOD-tg). Recombinant EPO (5 IU/g, R\&D Systems) or vehicle (saline) was admin- 

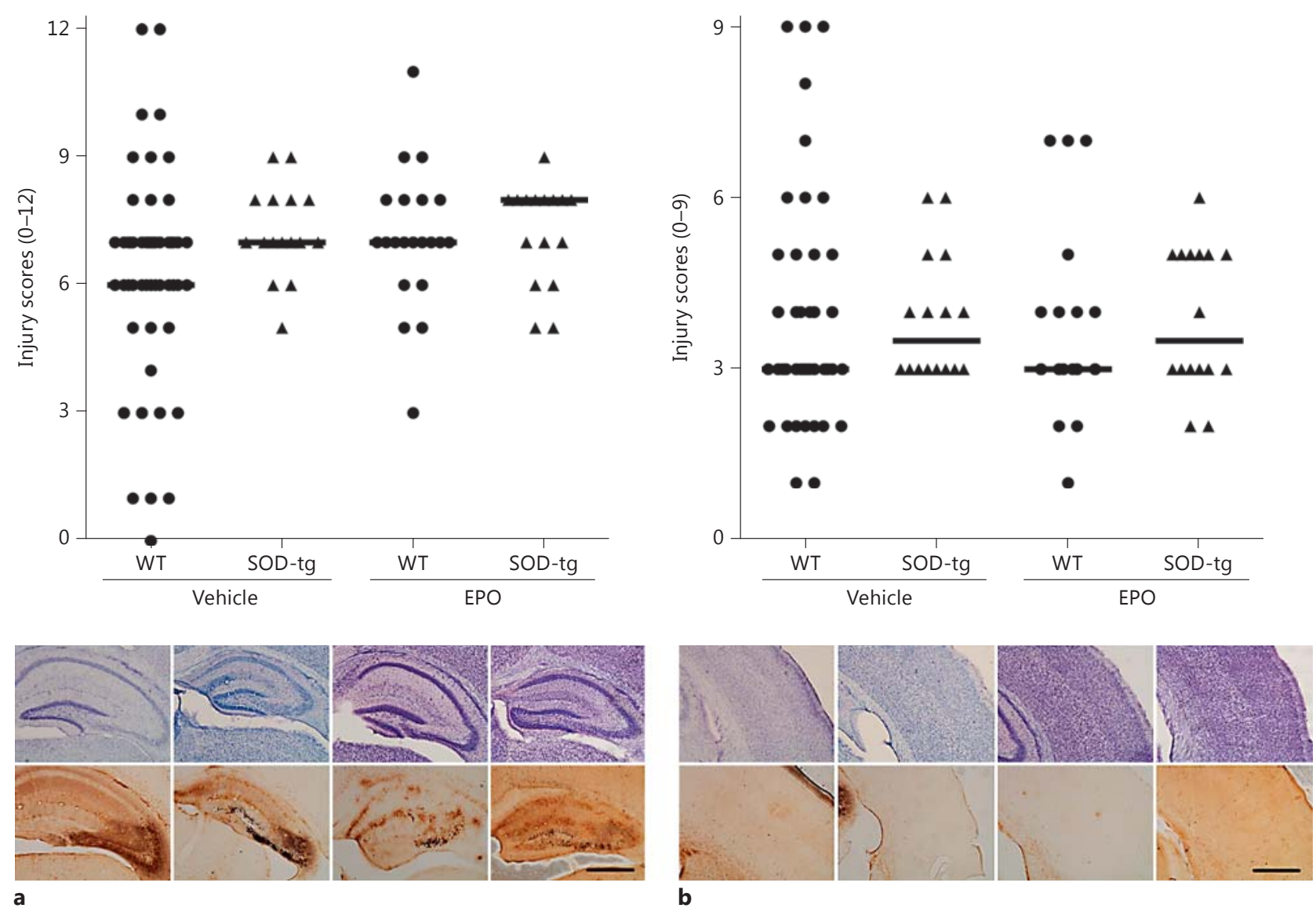

Fig. 2. Histological injury scores for the hippocampus (a, scale 0-12) and the cortex (b, scale 0-9) after HI with 50-min hypoxia. The horizontal line represents the median score. a In the hippocampus, SOD-tg + vehicle was more injured than WT + vehicle $(p<0.03)$, as was WT $+\mathrm{EPO}(p<0.04)$ and SOD-tg $+\mathrm{EPO}(p=$

istered 3 times, based on previous experiments in rats: immediately, at $24 \mathrm{~h}$, and at 5 days after hypoxia [30]. Mice were anesthetized with Euthasol (Virbac AH, Fort Worth, TX, USA) 7 days after $\mathrm{HI}$ and perfused transcardially with cold $4 \%$ paraformaldehyde in $0.1 \mathrm{M} \mathrm{PB}$; brains were removed, postfixed overnight, and stored at $4^{\circ} \mathrm{C}$ in $0.1 \mathrm{M} \mathrm{PB}$ until sectioning by Vibratome. Alternate 50- $\mu \mathrm{m}$ sections through the forebrain were collected for cresyl violet (Nissl) and Perl's (iron) histological stains to assess the degree of injury.

For Western blots, mice underwent $\mathrm{HI}$ as above, except all underwent 60 min of hypoxia and received only the immediate administration of EPO $(n=8 \mathrm{WT} ; n=6 \mathrm{SOD}-\mathrm{tg})$ or saline $(n=5 \mathrm{WT}$; $n=4$ SOD-tg). Sham mice $(n=3)$ were anesthetized and the left carotid artery was exposed but not ligated. Twenty-four hours after HI, mice were anesthetized with Euthasol, their brains rapidly removed, and the cortex and hippocampus from the injured side were dissected on a cold surface, frozen immediately, and then stored at $-80^{\circ} \mathrm{C}$.

0.02). b In the cortex, there were no differences between groups. Representative photomicrographs of injured hippocampus and cortex stained with cresyl violet (top row) or Perl's iron stain (bottom row) are shown below each group. Scale bar, $1 \mathrm{~mm}$.

\section{Histology and Injury Analysis}

All sections were examined for injury scoring to obtain a comprehensive view of brain injury (10-15 sections each, for both the cresyl violet and iron-stained sections). We modified our injury scoring system, previously used for the P7 mouse model, for the P9 model so as to reflect the different pattern of injury seen in the older animals. Specifically, we expanded the scoring of the striatum and added the thalamus; these are regions that demonstrate greater injury in the P9 mouse. Thus, 11 regions were assigned a score of $0-3$, with $0=$ no injury, $1=$ small focal areas of cell loss and iron deposition, 2 = patchy areas of cell loss in multiple areas of the region, and $3=$ cystic infarction, with a total score of $0-33$ for an injured hemisphere. The regions scored were the anterior, middle, and posterior cortex; CA1, CA2, CA3, and the dentate gyrus of the hippocampus; the anterior, middle, and posterior striatum; and the thalamus. 

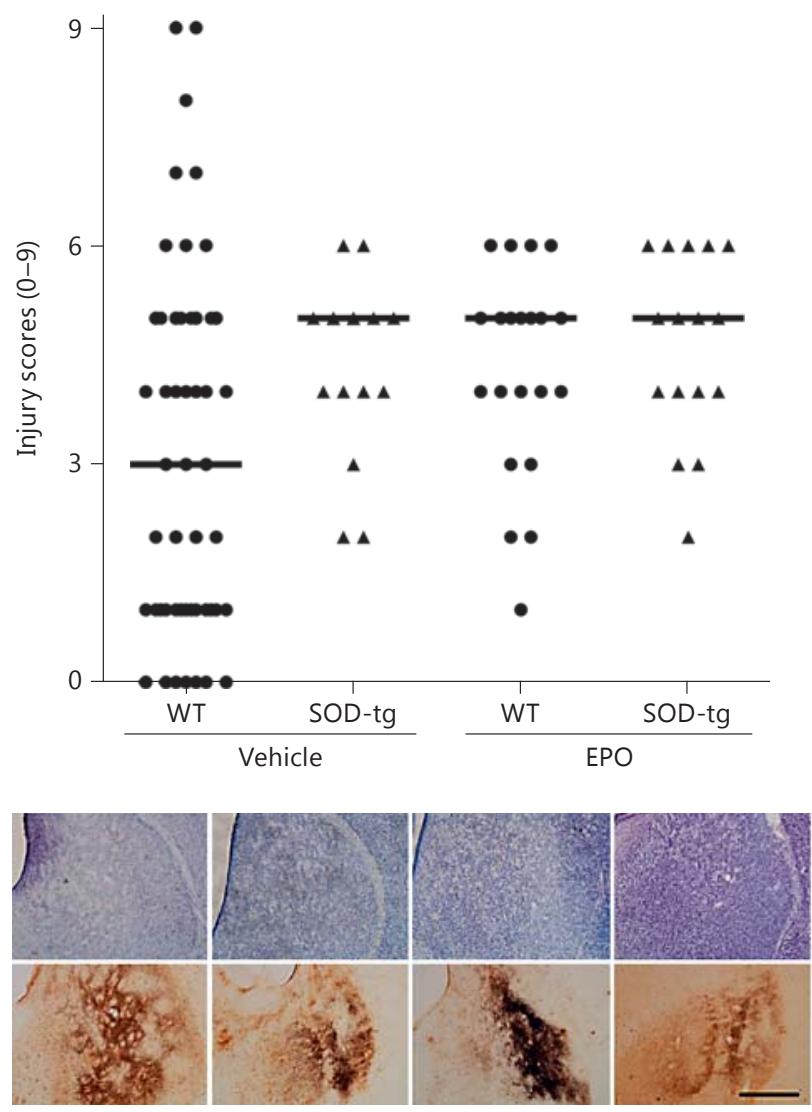

Fig. 3. Histological injury scores for the striatum (a, scale 0-9) and thalamus (b, scale 0-3) after HI with 50-min hypoxia. The horizontal line represents the median score. a In the striatum, SOD-tg + vehicle was more injured than WT + vehicle $(p<0.05)$, as was $\mathrm{WT}+\mathrm{EPO}(p<0.04)$ and SOD-tg + EPO $(p<0.02)$. b In the thal-

Western Blots

Brain tissue was homogenized with Dounce homogenizers using NE-PER cytoplasmic extraction reagents, with the addition of HALT protease and phosphatase inhibitors, according to the manufacturer's protocol (Thermo Scientific, Rockford, IL USA). After electrophoresis, proteins were transferred to PVDF membranes (Bio-Rad, Hercules, CA, USA). After blocking in 5\% non-fat dry milk in TBST for $1 \mathrm{~h}$, the membranes were incubated in blocking buffer containing antibodies recognizing EPO (1:500), EPOR (1:500), and $\beta$-actin (1:2,000) (all from Santa Cruz Biotechnology, Santa Cruz, CA, USA). Appropriate secondary HRP-conjugated antibodies $(1: 2,000)$ were used, and the signal was visualized with enhanced chemiluminescence. ImageJ was used to measure the optical density $(\mathrm{OD})$ of the blots on radiographic film after scanning.

Statistical Analysis

Injury scores were analyzed by the Mann-Whitney $U$ test. The OD of Western blots normalized to $\beta$-actin was analyzed by one-

EPO Exacerbates Injury in SOD

Transgenic Mice
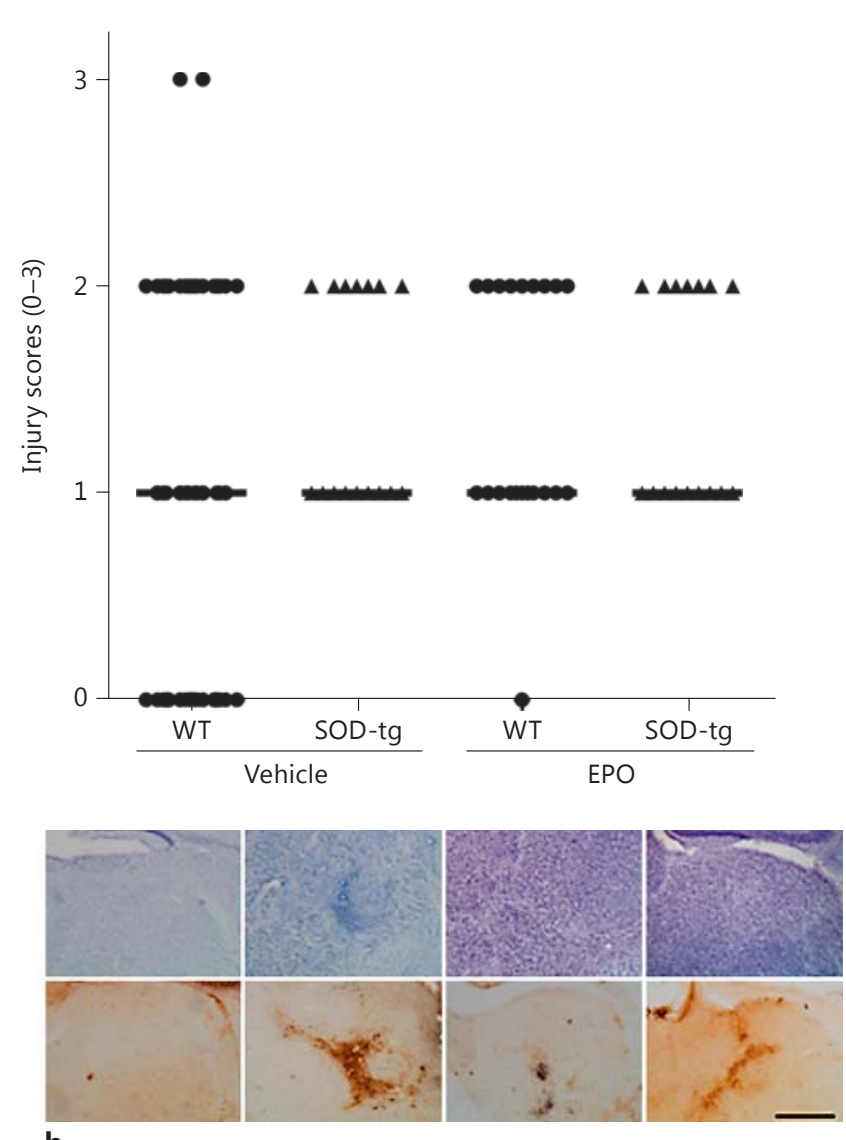

b

amus, there were no differences between groups. Representative photomicrographs of injured striatum and thalamus stained with cresyl violet (top row) or Perl's iron stain (bottom row) are shown below each group. Scale bar, $1 \mathrm{~mm}$.

way ANOVA with the Tukey test for multiple comparisons or the $t$ test, and are expressed as mean \pm SEM normalized to WT sham. Statistical analyses were performed with GraphPad Prism v7.0 (San Diego, CA, USA). $p<0.05$ was considered statistically significant.

\section{Results}

In the group subjected to moderate insult (50 min of hypoxia), the SOD-tg mice had greater injury than their WT littermates, confirming our previous study. EPO treatment did not decrease injury in SOD-tg or WT mice. Indeed, compared to WT + vehicle, injury was worse in both the WT mice and the overexpressors after EPO 


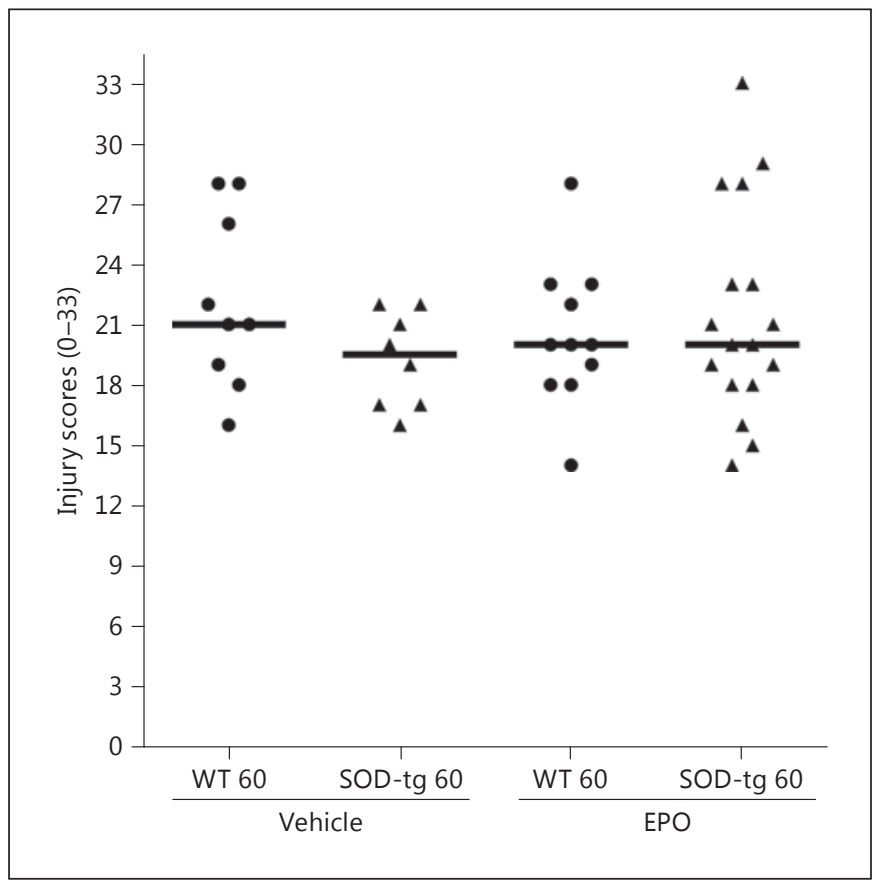

Fig. 4. Histological injury scores for the whole hemisphere after HI with 60 -min hypoxia (scale $0-33$ ). The horizontal line represents the median score. There were no differences between treatment groups.

(Fig. 1). The hippocampus showed similar results when analyzed separately. The SOD-tg mice had greater injury than the WT mice, and the injury was even worse in the SOD-tg + EPO and WT + EPO groups than in the WT + vehicle group (Fig. 2a). The cortex, however, showed milder injury than the other regions when analyzed separately, and injury here was similar in SOD-tg and WT mice; EPO treatment did not affect cortex injury (Fig. 2b). In the striatum, results were also similar as in the whole hemisphere, that is the SOD-tg mice had greater injury than the WT mice and the injury was worse in the SOD-tg + EPO and WT + EPO groups than in the WT + vehicle group (Fig. 3a). The thalamus displayed more consistent injury across groups, as they all had a median score of 1 (Fig. 3b).

Injury increased substantially in the groups subjected to the more severe insult ( $60 \mathrm{~min}$ of hypoxia), but there were no significant differences between treatment groups (Fig. 4). There were also no differences in the hippocampus (Fig. 5a), cortex (Fig. 5b), striatum (Fig. 6a), or thalamus (Fig. 6b) when analyzed separately.

We expanded our injury scoring system to reflect this different pattern of injury, increasing the potential score for the striatum and adding the thalamus (Table 1). With 50 min of hypoxia, the median injury score for all 56 WT + vehicle brains was 14 , slightly below the theoretical median of 16.5. The hippocampus median for all WT brains was 6 , precisely at the theoretical median, and the cortex median for all WT brains was 3 , well below the theoretical median of 4.5. The striatum median for all WT brains was 3 , below the theoretical median of 4.5 , but above that previously seen in the $\mathrm{P} 7$ model [31]. The thalamus median for all WT brains was 1, again below the theoretical median of 1.5, but the majority (62.5\%) displayed histological injury, unlike in the P7 model. Mortality was much lower in the $\mathrm{P} 9$ mouse model than in the $\mathrm{P} 7$ model, where it was typically $50 \%$ with the C57bl/6 strain [32].

\section{Expression of EPO and EPOR after HI}

In the cortex, EPO expression was higher $24 \mathrm{~h}$ after HI in the SOD + EPO group than in the SOD + vehicle group $(p=0.01$; Fig. $7 \mathrm{a})$, as was EPOR expression $(p<0.05$; Fig. 7b). In the hippocampus, there were no differences in EPO or EPOR expression (Fig. 7c, d).

\section{Mortality}

There was no mortality with the milder insult of 50 min of hypoxia. With the greater insult (60 min of hypoxia), 2 male WT and 1 female SOD-tg mouse died.

\section{Sex Differences}

There were no differences in injury scores between male and female mice when analyzed separately.

\section{Discussion}

With the more moderate injury induced by the $50-\mathrm{min}$ exposure to hypoxia after carotid ligation in $\mathrm{P} 9$ mice, we confirmed our previous result seen in P7 CD1 mice that the SOD-tg mice had greater injury than their WT littermates, despite the different background strain and $\mathrm{HI}$ paradigm. This was not seen with a more severe insult of 60-min exposure to hypoxia. We used a historical comparison of the P7 versus P9 models of HI. Specifically, in the P7 model, the cortex and hippocampus sustain the bulk of the injury, with cystic infarction in the cortex being common; in the hippocampus, injury is primarily to the pyramidal cell layer with the dentate gyrus being relatively spared. Injury is often comparatively mild in the striatum and thalamus in the $\mathrm{P} 7$ rodent $[32,33]$.

Since the overall injury was relatively mild with $50 \mathrm{~min}$ of hypoxia, we repeated the experiments with a stronger 

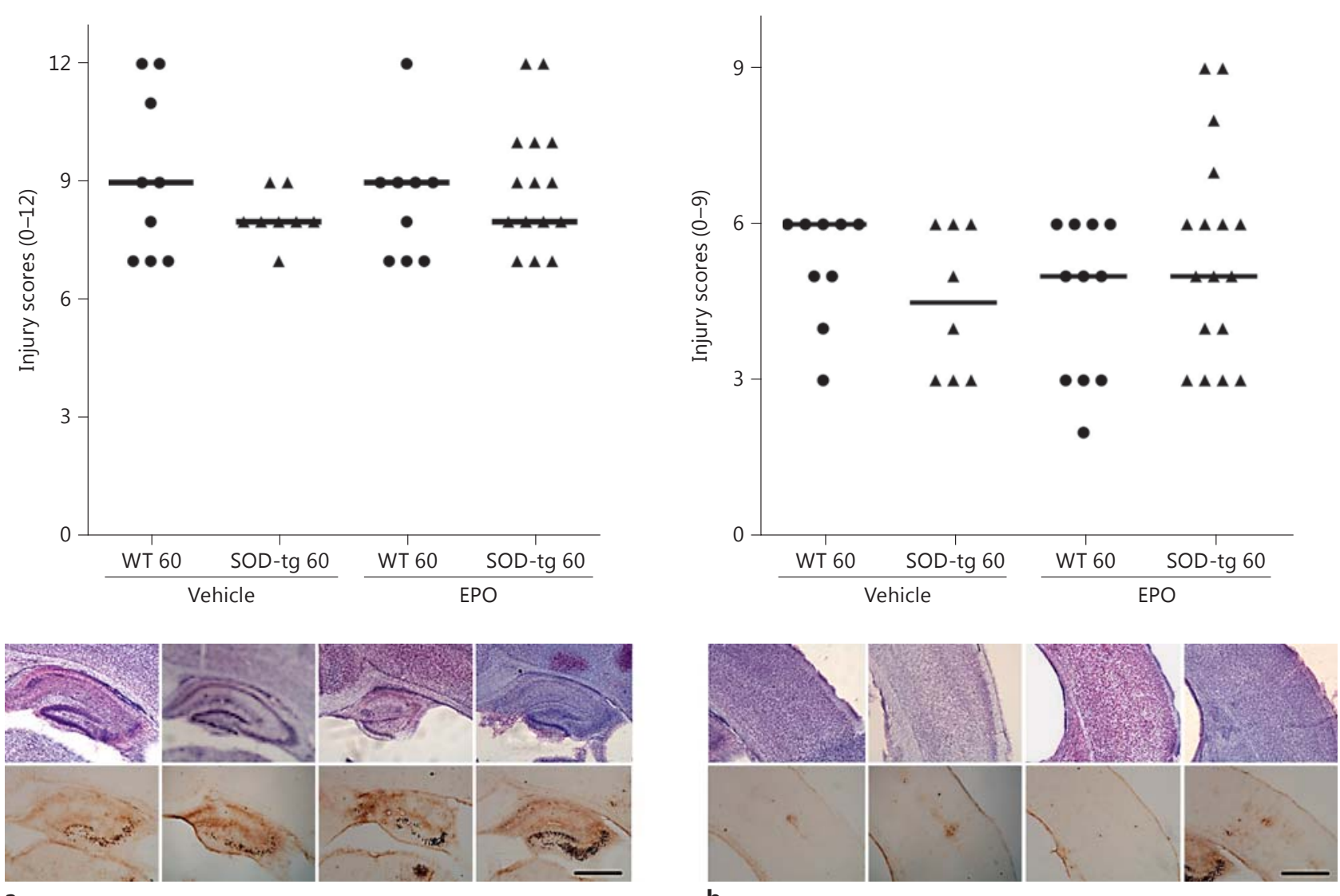

b

Fig. 5. Histological injury scores for the hippocampus (a, scale 0-12) and cortex (b, scale 0-9) after HI with 60-min hypoxia. The horizontal line represents the median score. There were no differences between groups in the hippocampus or cortex. Representa- tive photomicrographs of injured hippocampus and cortex stained with cresyl violet (top row) or Perl's iron stain (bottom row) are shown below each group. Scale bar, $1 \mathrm{~mm}$. insult (i.e., $60 \mathrm{~min}$ of hypoxia). Injury was indeed increased and the appearance of cystic infarction also increased accordingly; 22 out of 45 brains ( $46 \%$ ) had cystic infarction in $\geq 1$ regions. The WT + vehicle brains had the greatest increase in injury with the longer hypoxia exposure, sustaining a $50 \%$ increase in median score for the whole hemisphere as well as in the hippocampus, cortex, striatum, and thalamus. The increase in injury was more moderate in the SOD-tg + vehicle (15\%), WT + EPO (25\%), and SOD-tg + EPO (8\%) groups. These groups showed greater injury in the 50-min hypoxia experiments in comparison to the WT + vehicle group, suggesting that the increased oxidative stress did not further increase injury in these groups beyond that of the WT + vehicle group. Consequently, differences between treatment groups were lost with the more severe insult, perhaps suggesting that a greater susceptibility to oxidative stress can be seen not only between P7 (preterm human model) and adult rodents [4], but also between the preterm and term models (P9). The Western blots were all done with $60 \mathrm{~min}$ of hypoxia, limiting these results to the more severe injury paradigm.

Despite other animal studies showing improvements with EPO, especially in stroke models [13], 2 studies on rats treated with hypothermia and EPO showed no added improvement of EPO over hypothermia only [34, 35]. Much of the work showing improvement with EPO in $\mathrm{HI}$ has been in the P7 rat model $[15,36,37]$. The difference in age as small as that between $\mathrm{P} 7$ and $\mathrm{P} 9$ has a significant effect on outcome. One study in P9 mice showed 


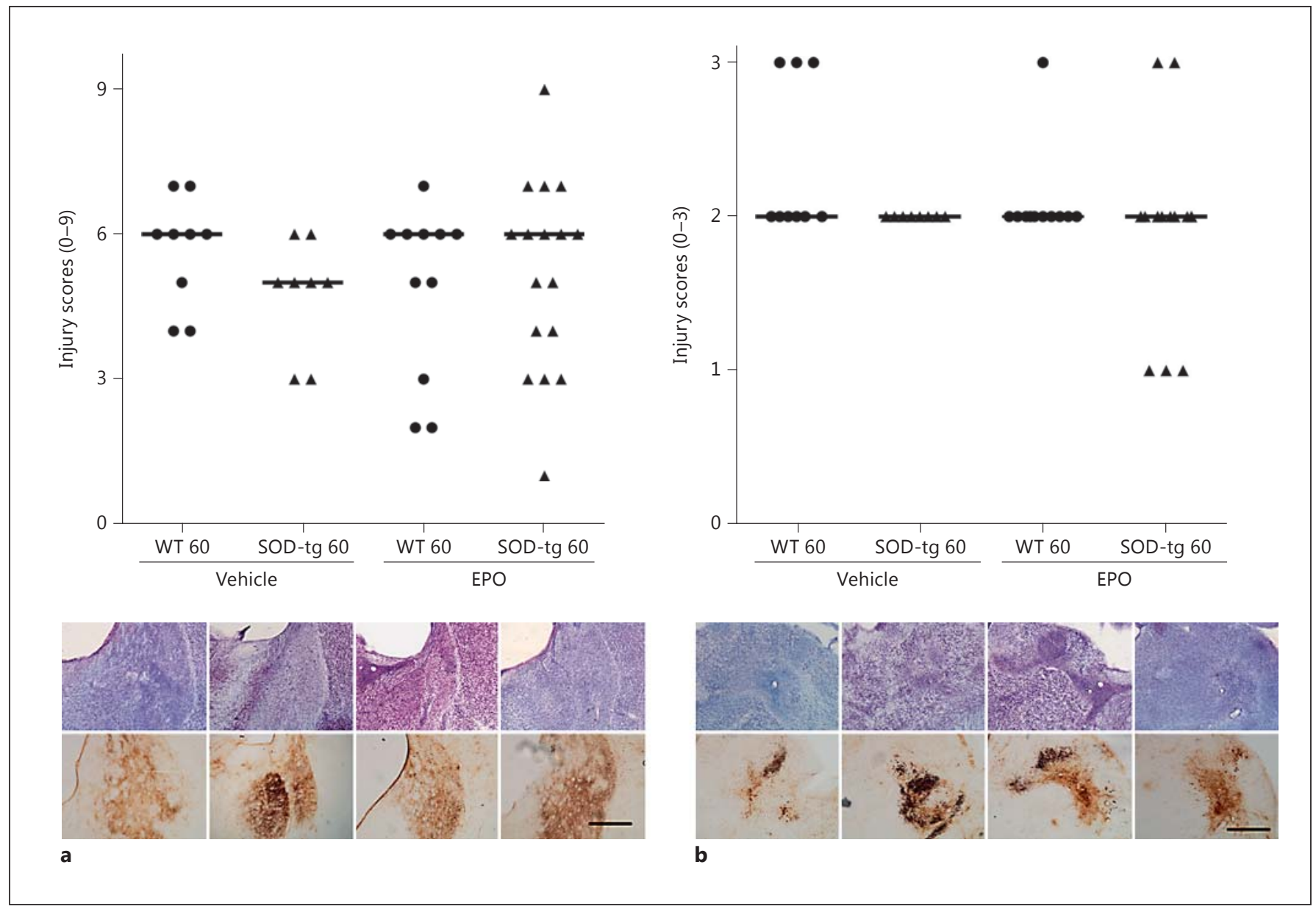

Fig. 6. Histological injury scores for the striatum (a, scale 0-9) and thalamus (b, scale $0-3$ ) after HI with 60 min of hypoxia. The horizontal line represents the median score. There were no differenc-

photomicrographs of injured striatum and thalamus stained with cresyl violet (top row) or Perl's iron stain (bottom row) are shown below each group. Scale bar, $1 \mathrm{~mm}$.

Table 1. Median injury score (range) and $p$ value for each treatment group

\begin{tabular}{|c|c|c|c|c|c|c|c|c|}
\hline \multirow{2}{*}{$\begin{array}{l}\text { Injured } \\
\text { region }\end{array}$} & \multicolumn{4}{|c|}{ 50-min hypoxia } & \multicolumn{4}{|c|}{ 60-min hypoxia } \\
\hline & $\begin{array}{l}\text { WT + } \\
\text { vehicle }\end{array}$ & $\begin{array}{l}\text { SOD-tg + } \\
\text { vehicle }\end{array}$ & $\mathrm{WT}+\mathrm{EPO}$ & $\begin{array}{l}\text { SOD-tg + } \\
\text { EPO }\end{array}$ & $\begin{array}{l}\text { WT + } \\
\text { vehicle }\end{array}$ & $\begin{array}{l}\text { SOD-tg + } \\
\text { vehicle }\end{array}$ & $\mathrm{WT}+\mathrm{EPO}$ & $\begin{array}{l}\text { SOD-tg + } \\
\text { EPO }\end{array}$ \\
\hline $\begin{array}{l}\text { Whole } \\
\text { hemisphere }\end{array}$ & $14(3-33)$ & $\begin{array}{l}17(10-22) \\
p<0.03\end{array}$ & $\begin{array}{l}16(9-25) \\
p<0.05\end{array}$ & $\begin{array}{l}18.5(10-21) \\
p=0.01\end{array}$ & $21(16-28)$ & $19.5(16-22)$ & $20(14-28)$ & $20(14-33)$ \\
\hline Hippocampus & $6(0-12)$ & $\begin{array}{l}7(5-9) \\
p<0.03\end{array}$ & $\begin{array}{l}7(3-11) \\
p<0.04\end{array}$ & $\begin{array}{l}8(5-9) \\
p=0.02\end{array}$ & $9(7-12)$ & $8(7-9)$ & $9(7-12)$ & $8(7-12)$ \\
\hline Cortex & $3(1-9)$ & $3.5(3-6)$ & $3(1-7)$ & $4.5(2-6)$ & $6(3-6)$ & $4.5(3-6)$ & $5(2-6)$ & $5(3-9)$ \\
\hline Striatum & $3(0-9)$ & $\begin{array}{l}5(2-6) \\
p<0.05\end{array}$ & $\begin{array}{l}5(1-6) \\
p<0.04\end{array}$ & $\begin{array}{l}5(2-6) \\
p<0.02\end{array}$ & $6(4-7)$ & $5(3-6)$ & $6(2-7)$ & $6(1-9)$ \\
\hline Thalamus & $1(0-3)$ & $1(1-2)$ & $1(0-2)$ & $1(1-2)$ & $2(2-3)$ & $2(2-2)$ & $2(2-3)$ & $2(1-3)$ \\
\hline
\end{tabular}




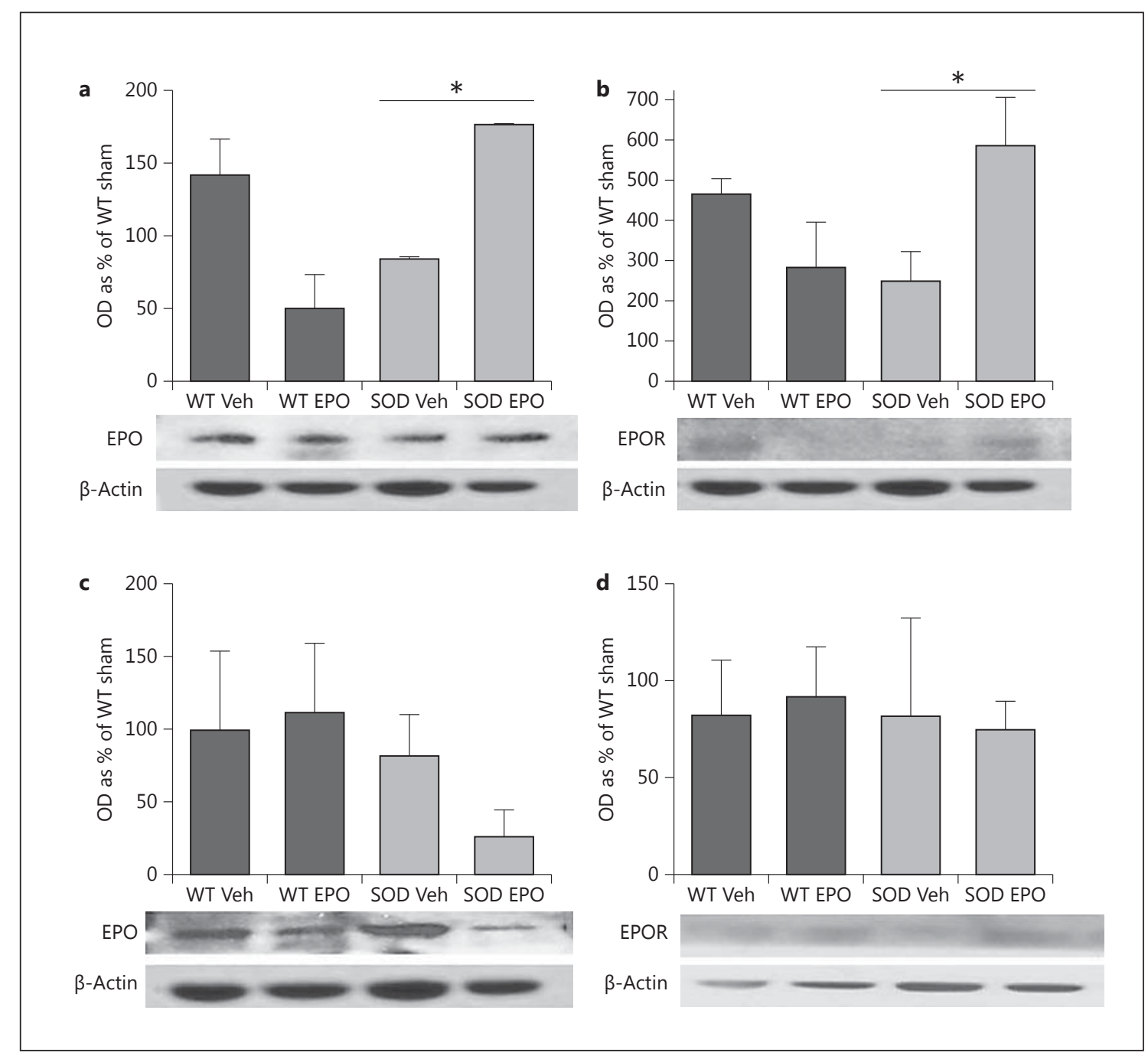

Fig. 7. Protein expression in the cortex (a, b) and hippocampus (c, d) $24 \mathrm{~h}$ after HI normalized to WT sham. a EPO expression is higher in SOD-tg + EPO $(* p<0.01)$ than in SOD + vehicle. b EPOR expression is also higher in SOD-tg + EPO $(* p<0.05)$ than in SOD + vehicle. c EPO expression in the hippocampus did not differ across treatment groups. d EPOR expression was not different across treatment groups. WT Veh, wild-type + vehicle; WT EPO, wild-type + erythropoietin; SOD Veh, superoxide dismutase + vehicle; SOD EPO, superoxide dismutase + erythropoietin.

improvements only in female mice [18]. The injury created in these models is not as severe as that seen in this study at a different age. Indeed, an association of age with the severity of injury has shown mixed results in human studies. In a recent study of early prophylactic high-dose EPO in very preterm infants, there were no statistically significant differences in neurodevelopmental outcomes at 2 years, despite positive changes in MRI at earlier ages between the placebo- and EPO-treated groups [38].

In this study, there was no improvement in injury scores with EPO treatment, and with prolonged hypoxic

EPO Exacerbates Injury in SOD

Transgenic Mice insults, there was worsened injury, despite an increase in EPO levels in the cortex. These findings suggest that in situations of extreme hypoxic-ischemic damage, there is little chance of rescue with these neuroprotective therapies. In situations with more moderate insults, therapies such as EPO may be able to impact the trajectory of damage. These important findings suggest that EPO may not be beneficial in situations of extreme oxidative stress when used immediately after the insult. Possibly, exogenous EPO treatment during the early phase interferes with endogenous repair responses and consequently

Dev Neurosci 2017;39:228-237 DOI: $10.1159 / 000472710$ 
worsens the injury. Given the variety of results, continued studies with EPO, especially those on hypoxic-ischemic encephalopathy, are warranted. Attention should be paid to differences in developmental age, species, and strain, as well as the dosage and timing of EPO administration. In particular, delayed rather than immediate EPO treatment has greater clinical relevance and may enhance repair mechanisms, especially when multiple doses are given over days or weeks [14].

\section{Acknowledgements}

Breeding pairs of SOD1-tg mice were generously provided by Pak H. Chan, PhD. Technical assistance was provided by Pamela G. Lagera. This research was supported by NS33997 (D.M.F.), Fondation Leducq (D.M.F.), the Basque Government (BFI-2011129) (O.A.C.), and the University of Ulsan College of Medicine (B.S.L.).

\section{Disclosure Statement}

The authors have no conflict of interests to disclose.

\section{References}

1 Kinouchi H, Epstein CJ, Mizui T, Carlson E, Chen SF, Chan PH: Attenuation of focal cerebral ischemic injury in transgenic mice overexpressing CuZn superoxide dismutase. Proc Natl Acad Sci USA 1991;88:11158-11162.

2 Ditelberg JS, Sheldon RA, Epstein CJ, Ferriero DM: Brain injury after perinatal hypoxiaischemia is exacerbated in copper/zinc superoxide dismutase transgenic mice. Pediatr Res 1996;39:204-208.

3 Fullerton HJ, Ditelberg JS, Chen SF, Sarco DP, Chan PH, Epstein CJ, Ferriero DM: Copper/ zinc superoxide dismutase transgenic brain accumulates hydrogen peroxide after perinatal hypoxia ischemia. Ann Neurol 1998;44: 357-364.

4 Lafemina MJ, Sheldon RA, Ferriero DM: Acute hypoxia-ischemia results in hydrogen peroxide accumulation in neonatal but not adult mouse brain. Pediatr Res 2006;59:680-683.

5 Emerling BM, Platanias LC, Black E, Nebreda AR, Davis RJ, Chandel NS: Mitochondrial reactive oxygen species activation of p38 mitogen-activated protein kinase is required for hypoxia signaling. Mol Cell Biol 2005;25: 4853-4862.

6 Chang S, Jiang X, Zhao C, Lee C, Ferriero DM: Exogenous low dose hydrogen peroxide increases hypoxia-inducible factor-1alpha protein expression and induces preconditioning protection against ischemia in primary cortical neurons. Neurosci Lett 2008;441:134-138.

7 Morishita E, Masuda S, Nagao M, Yasuda Y, Sasaki R: Erythropoietin receptor is expressed in rat hippocampal and cerebral cortical neurons, and erythropoietin prevents in vitro glutamate-induced neuronal death. Neuroscience 1997;76:105-116.

8 Koshimura K, Murakami Y, Sohmiya M, Tanaka J, Kato Y: Effects of erythropoietin on neuronal activity. J Neurochem 1999;72: 2565-2572.

9 Liu R, Suzuki A, Guo Z, Mizuno Y, Urabe T: Intrinsic and extrinsic erythropoietin enhances neuroprotection against ischemia and reperfusion injury in vitro. J Neurochem 2006;96:1101-1110.
10 Osredkar D, Sall JW, Bickler PE, Ferriero DM: Erythropoietin promotes hippocampal neurogenesis in in vitro models of neonatal stroke. Neurobiol Dis 2010;38:259-265.

11 Chang YS, Mu D, Wendland M, Sheldon RA, Vexler ZS, McQuillen PS, Ferriero DM: Erythropoietin improves functional and histological outcome in neonatal stroke. Pediatr Res 2005;58:106-111.

12 Sola A, Rogido M, Lee BH, Genetta T, Wen TC: Erythropoietin after focal cerebral ischemia activates the Janus kinase-signal transducer and activator of transcription signaling pathway and improves brain injury in postnatal day 7 rats. Pediatr Res 2005;57:481-487.

13 Gonzalez FF, Larpthaveesarp A, McQuillen P, Derugin N, Wendland M, Spadafora R, Ferriero DM: Erythropoietin increases neurogenesis and oligodendrogliosis of subventricular zone precursor cells after neonatal stroke. Stroke 2013;44:753-758.

14 Larpthaveesarp A, Georgevits M, Ferriero DM, Gonzalez FF: Delayed erythropoietin therapy improves histological and behavioral outcomes after transient neonatal stroke. Neurobiol Dis 2016;93:57-63.

15 Kumral A, Ozer E, Yilmaz O, Akhisaroglu M, Gokmen N, Duman N, Ulukus C, Genc S, Ozkan H: Neuroprotective effect of erythropoietin on hypoxic-ischemic brain injury in neonatal rats. Biol Neonate 2003;83:224-228.

16 Matsushita H, Johnston MV, Lange MS, Wilson MA: Protective effect of erythropoietin in neonatal hypoxic ischemia in mice. Neuroreport 2003;14:1757-1761.

17 Iwai M, Cao G, Yin W, Stetler RA, Liu J, Chen J: Erythropoietin promotes neuronal replacement through revascularization and neurogenesis after neonatal hypoxia/ischemia in rats. Stroke 2007;38:2795-2803.

18 Fan X, Heijnen CJ, van der KM, Groenendaal F, van Bel F: Beneficial effect of erythropoietin on sensorimotor function and white matter after hypoxia-ischemia in neonatal mice. Pediatr Res 2011;69:56-61.
19 Lan KM, Tien LT, Cai Z, Lin S, Pang Y, Tanaka S, Rhodes PG, Bhatt AJ, Savich RD, Fan LW: Erythropoietin ameliorates neonatal hypoxia-ischemia-induced neurobehavioral deficits, neuroinflammation, and hippocampal injury in the juvenile rat. Int J Mol Sci 2016;17:289.

20 Wang L, Zhang Z, Wang Y, Zhang R, Chopp M: Treatment of stroke with erythropoietin enhances neurogenesis and angiogenesis and improves neurological function in rats. Stroke 2004;35:1732-1737.

21 Osredkar D, Thoresen M, Maes E, Flatebo T, Elstad M, Sabir H: Hypothermia is not neuroprotective after infection-sensitized neonatal hypoxic-ischemic brain injury. Resuscitation 2014;85:567-572.

22 Xiong T, Qu Y, Mu D, Ferriero D: Erythropoietin for neonatal brain injury: opportunity and challenge. Int J Dev Neurosci 2011;29: 583-591.

23 Traudt CM, McPherson RJ, Bauer LA, Richards TL, Burbacher TM, McAdams RM, Juul SE: Concurrent erythropoietin and hypothermia treatment improve outcomes in a term nonhuman primate model of perinatal asphyxia. Dev Neurosci 2013;35:491-503.

24 Wu YW, Gonzalez FF: Erythropoietin: a novel therapy for hypoxic-ischaemic encephalopathy? Dev Med Child Neurol 2015;57(suppl 3):34-39.

$25 \mathrm{Wu}$ YW, Mathur AM, Chang T, McKinstry RC, Mulkey SB, Mayock DE, Van Meurs KP, Rogers EE, Gonzalez FF, Comstock BA, Juul SE, Msall ME, Bonifacio SL, Glass HC, Massaro AN, Dong L, Tan KW, Heagerty PJ, Ballard RA: High-dose erythropoietin and hypothermia for hypoxic-ischemic encephalopathy: a phase II trial. Pediatrics 2016;137: e20160191.

26 Epstein CJ, Avraham KB, Lovett M, Smith S, Elroy-Stein O, Rotman G, Bry C, Groner Y: Transgenic mice with increased $\mathrm{Cu} / \mathrm{Zn}$-superoxide dismutase activity: animal model of dosage effects in Down syndrome. Proc Natl Acad Sci USA 1987;84:8044-8048. 
27 Elroy-Stein O, Bernstein Y, Groner Y: Overproduction of human $\mathrm{Cu} / \mathrm{Zn}$-superoxide dismutase in transfected cells: extenuation of paraquat-mediated cytotoxicity and enhancement of lipid peroxidation. EMBO J 1986;5: 615-622.

28 Rice JE 3rd, Vannucci RC, Brierley JB: The influence of immaturity on hypoxic-ischemic brain damage in the rat. Ann Neurol 1981;9: 131-141.

29 Wang X, Zhu C, Hagberg H, Korhonen L, Sandberg M, Lindholm D, Blomgren K: Xlinked inhibitor of apoptosis (XIAP) protein protects against caspase activation and tissue loss after neonatal hypoxia-ischemia. Neurobiol Dis 2004;16:179-189.

30 Gonzalez FF, Abel R, Almli CR, Mu D, Wendland M, Ferriero DM: Erythropoietin sustains cognitive function and brain volume after neonatal stroke. Dev Neurosci 2009;31:403411.
31 Sheldon RA, Almli L, Ferriero DM: Copper/ zinc superoxide dismutase transgenic brain in neonatal hypoxia-ischemia. Methods Enzymol 2002;353:389-397.

32 Sheldon RA, Sedik C, Ferriero DM: Strainrelated brain injury in neonatal mice subjected to hypoxia-ischemia. Brain Res 1998;810: 114-122.

33 Stone BS, Zhang J, Mack DW, Mori S, Martin LJ, Northington FJ: Delayed neural network degeneration after neonatal hypoxia-ischemia. Ann Neurol 2008;64:535-546.

34 Fang AY, Gonzalez FF, Sheldon RA, Ferriero DM: Effects of combination therapy using hypothermia and erythropoietin in a rat model of neonatal hypoxia-ischemia. Pediatr Res 2013;73:12-17.

35 Fan X, van Bel F, van der Kooij MA, Heijnen CJ, Groenendaal F: Hypothermia and erythropoietin for neuroprotection after neonatal brain damage. Pediatr Res 2013;73:18-23.
36 Aydin A, Genc K, Akhisaroglu M, Yorukoglu K, Gokmen N, Gonullu E: Erythropoietin exerts neuroprotective effect in neonatal rat model of hypoxic-ischemic brain injury. Brain Dev 2003;25:494-498.

37 Kumral A, Gonenc S, Acikgoz O, Sonmez A, Genc K, Yilmaz O, Gokmen N, Duman N, Ozkan H: Erythropoietin increases glutathione peroxidase enzyme activity and decreases lipid peroxidation levels in hypoxic-ischemic brain injury in neonatal rats. Biol Neonate 2005;87:15-18

38 Natalucci G, Latal B, Koller B, Ruegger C, Sick B, Held L, Bucher HU, Fauchere JC, Swiss EPONTG: Effect of early prophylactic highdose recombinant human erythropoietin in very preterm infants on neurodevelopmental outcome at 2 years: a randomized clinical trial. JAMA 2016;315:2079-2085. 